\title{
Production of skin lotions/creams from Hammam Jalli's mud
}

\author{
Mohammed H. S. Zangana ${ }^{1}$, Fakhri H. Ibraheem ${ }^{1}$, \\ Abdulrahman Kh. Perot ${ }^{1}$, Kanabi O. Ibrahim ${ }^{1}$ \\ \& Fuad M. Khoshnaw ${ }^{2}$ \\ ${ }^{1}$ Chemical Engineering Department, Faculty of Engineering, \\ Koya University, Kurdistan-Iraq \\ ${ }^{2}$ Manufacturing Engineering Department, Faculty of Engineering, \\ Koya University, Kurdistan-Iraq
}

\begin{abstract}
There are a number of natural springs throughout the Kurdistan region. They are located in different geographical areas and each of them may differ from another in odder and mineral contents. These springs are known by locals in Kurdistan under various names, for example, Hammam, Garaw, Ganaw or Ganau. Hammam Jalli is one of these springs which is located near the city of Koya and is attracting thousands of local people every year, mainly, those who are suffering from skin diseases such as psoriasis, urticaria, leucoderma, eczema, acne, dermatitis, etc. Both the water and the mud of Hammam Jalli have been used as treatment or as cosmetics, However, their therapeutic effects is not fully understood and, according to the authors' knowledge, there has been no scientific research work in such detail prior to this study. The microbiological testing results show that the Hammam Jalli's water is fully contaminated with harmful bacteria including E. coli, therefore, it must be treated before it can be used for human consumption. The temperature measurement results show a large temperature difference between the Hammam Jalli's water and the temperature of the surrounding air which can lead to a conclusion that Hammam Jalli can be introduced as a hot spring. This being the case, this spring can be turned into a popular tourist destination for locals and international tourism. In the current work also efforts were made to suggest a suitable process flow diagram (PFD) for the production of skin lotions/creams from Hammam Jalli's mud and water. Keywords: Hammam Jalli, attractions in Kurdistan, Koya city, hot spring, skin care, lotions and creams, cosmetics.
\end{abstract}




\section{Introduction}

The skin is the largest human organ, and it fulfills various important functions. In addition to protecting against injury, environmental influences, dehydration, and desiccation, the skin serves to combat infection, regulate body temperature, and transmit sensory stimuli [1].

Skin can absorb chemicals into the blood stream, causing toxic effects [2], therefore, it is important to avoid cancer-causing, toxic, synthetic and chemical ingredients in cosmetics and skin care products. Various skin care products can be made from the thermal mud which has an extremely high mineral content such as alumina, calcium, iron, magnesium, phosphorus, potassium, silica, sodium, sulfur and titanium. Sulfur is an essential mineral that plays an important role in the health of skin specially for treating acne, eczema and other skin related complaints. People who are suffering from skin diseases can obtain relief by having a mud baths. Mud is applied to the affected skin areas (Figure 1), left on for several minutes and then washed off.

While the exact year of its inception is unknown, mud baths have existed for thousands of years. Historically, the mud baths have been used for centuries to treat a number of skin diseases for example psoriasis, urticaria, leucoderma, eczema, acne, dermatitis, etc [3]; this is in addition to their beautifying effects on the skin.

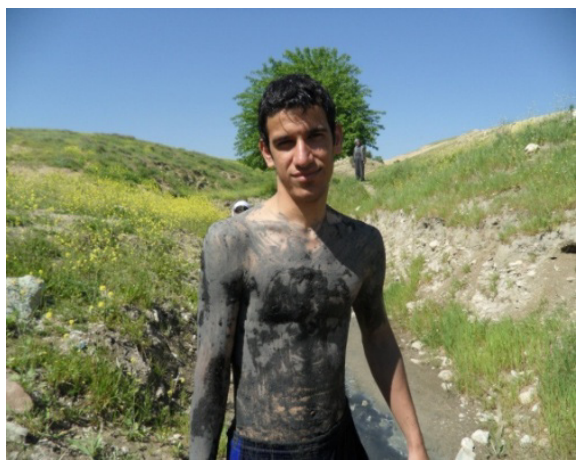

Figure 1: $\quad$ Local people applying Hammam Jalli’s mud to their skin.

A hot spring or thermal spring is defined in a number of ways; the most accepted definition can be that the hot spring is a natural spring producing water at a temperature substantially greater than the air temperature of the surrounding region or at a temperature above that of the human body. Hot springs are formed naturally when water seeps kilometers deep into the earth, where it is heated and pressurized, the water is forced back to the surface, laden with sulphate, calcium, bicarbonate, magnesium, sodium and other natural minerals (Figure 2). Most hot springs discharge groundwater that is heated by shallow intrusions of magma (molten rock) in volcanic areas. Some thermal springs, however, are not related 
to volcanic activity. In such cases, the water is heated by convective circulation: ground water is percolating downward reaches depths of a kilometer or more where the temperature of rocks is high because of the normal temperature gradient of the Earth's crust [4].

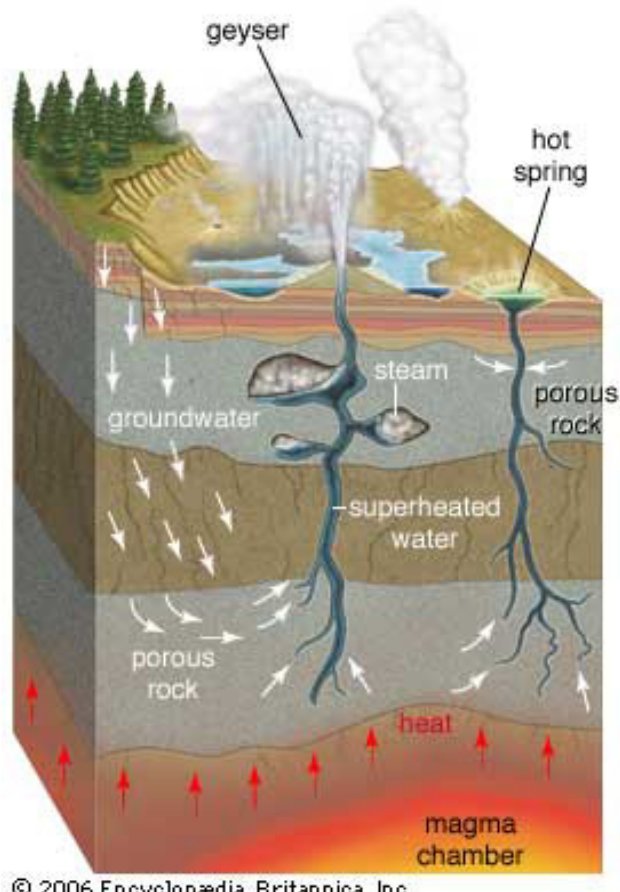

(9) 2006 Encyclopædia Britannica, Inc.

Figure 2: $\quad$ Magma chamber: cross section of geyser and hot spring.

Hot springs can be found in many countries around the world such as in Iceland, New Zealand, Chile, Hungary, and Japan. These springs became popular tourist destinations over the last decades due to their claimed medicinal and therapeutic values. In the Kurdistan region also there are a number of natural springs that are visited by locals because of their healing properties; Hammam Jalli which is located $15 \mathrm{~km}$, north of the city of Koya and $70 \mathrm{~km}$, in the east of Erbil is one of these springs (Figure 3). Both the water and the mud of Hammam Jalli have been used by local people as treatment, or cosmetics (Figure 4), especially, by those who are suffering from skin diseases. So far, the therapeutic effects of Hammam Jalli's water and mud on the skin diseases is not fully understood and according to the authors knowledge there is no scientific research work prior to this study. Both the water and the mud can be contaminated with many harmful substances such as bacteria, viruses, fungi or chemicals that can cause bad side effects on the human's body. Therefore, this study aimed at; 
analyzing Hammam Jalli's water and mud both microbiologically and chemically, and treat them accordingly to meet the Iraqi standards of quality (IQS-2079) and (IQS-1161). Meanwhile, studying the thermal behavior of this spring and suggesting a suitable process flow diagram (PFD) for production of skin lotions/creams from Hammam Jalli’s mud and water.
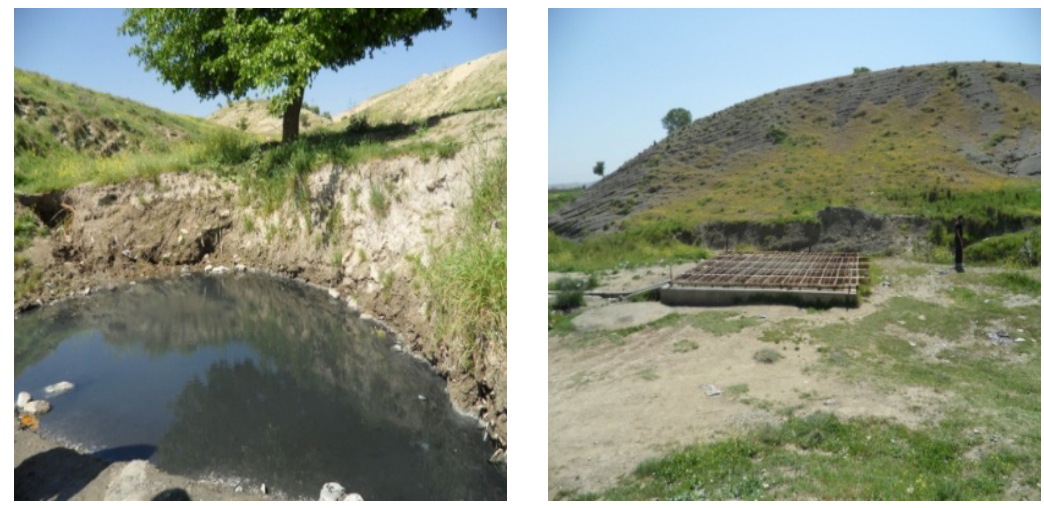

Figure 3: $\quad$ Site view of Hammam Jalli.
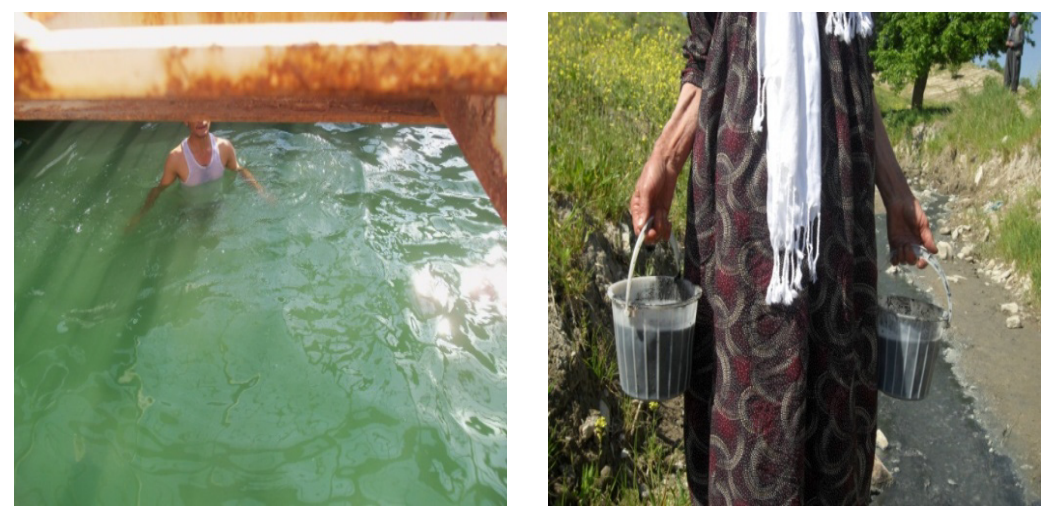

Figure 4: $\quad$ Hammam Jalli’s mud and water for therapeutic purposes.

\section{The expected impacts}

This study is expected to have the following impacts:

i. This study can provide scientific evidence on the medicinal values of Hammam Jalli's water and mud and proposes a solution to make this natural spring microbiologically safe.

ii. Can play a significant role in Introducing Hammam Jalli as a hot spring which can be turned into a popular tourist destination for locals and international tourism. 
iii. Can make Hammam Jalli's skin care products such as skin lotions and skin creams commercially available.

\section{Preliminary results and discussion}

\subsection{Temperature measurements}

During the present study, the water temperature of Hammam Jalli and the air temperature of the surrounding region were measured in situ using a digital thermometer type (TP 3001). The temperature measurement results shown that the temperature difference between the Hammam Jalli's water and the air temperature of the surrounding region is larger than $15^{\circ} \mathrm{C}$. According to this result and based on the definitions stated previously it can be concluded that Hammam Jalli can be introduced as one of the hot springs in the Kurdistan region which can be turned into a popular tourist destination.

\subsection{Microbiological testing}

Water and mud samples from Hammam Jalli have been examined microbiologically. The results show that the water is contaminated with harmful Bacteria such as E. coli. Therefore, it must be treated before it can be used for human consumptions including the external uses, i.e. for therapeutic purposes, and even for irrigation uses. Based on what have been mentioned, samples from Hammam Jalli's water and mud were treated with chlorine of various amounts, more than 25 PPM of chlorine were needed for these types of bacteria to be eliminated completely.

\subsection{Process block diagram}

Figure 5 shows the suggested production stages of skin lotions/creams from Hammam Jalli's water and mud. The production process consists of

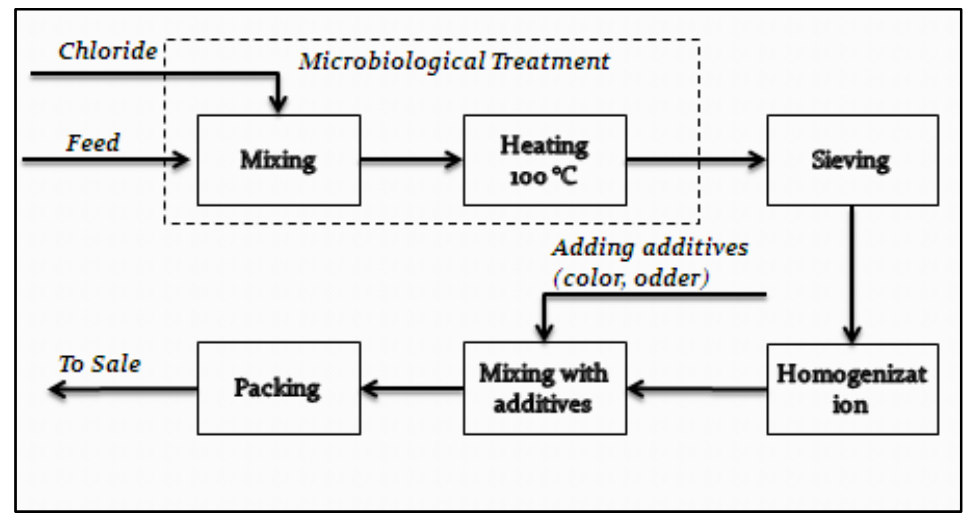

Figure 5: $\quad$ Process block diagram of production of skin lotions/creams from Hammam Jalli's mud and water. 
microbiological treatment, drying and sieving, homogenization, adding additives, such as colour and odder and finally the packing and labelling. The final product, however, must be tested for quality assurance before it can be released to the market.

\section{References}

[1] Günther Schneider, Sven Gohla, Jörg Schreiber, Waltraud Kaden, Uwe Schönrock, Hartmut Schmidt-Lewerkühne, Annegret Kuschel, Xenia Petsitis, Wolfgang Pape, Hellmut Ippen and Walter Diembeck "Skin Cosmetics” in Ullmann's Encyclopedia of Industrial Chemistry (2005) Wiley-VCH, Weinheim.

[2] Carson, P. A., \& Mumford, C. J. (2002). "Hazardous Chemicals Handbook”. Oxford: Butterworth-Heinemann.

[3] Chadzopulu A., Adraniotis J., Theodosopoulou E., (2011), “The therapeutic effects of mud” Progress in Health Sciences Vol. 1(2), pp 132-136.

[4] Hot spring, (2013). Encyclopcedia Britannica Online. Retrieved 13 September, 2013, from http://www.britannica.com/EBchecked/topic/272775 /hot-spring 